\title{
Functional Structure from Top to Toe
}

\author{
Peter Svenonius \\ CASTL, University of Troms $\varnothing$
}

August 26, 2013

\section{Tarald's work}

The chapters in this volume are a fitting tribute to the work of Tarald Taraldsen, who has been publishing brilliant solutions to linguistic puzzles for about thirtyfive years. In this introductory chapter, I first summarize some of Tarald's work to provide background for the other chapters in the volume, before moving on to describe them.

Tarald's work is the epitome of the modern, comparative, 'Principles \& Parameters' enterprise. He approaches linguistic data the way a good detective in a mystery novel approaches evidence: nothing is presumed to be accidental, every piece of linguistic data is potentially a clue to the larger structure of things, and though the ultimate solution will be elegant once all the pieces fall into place, the path there is never presumed to be straightforward or obvious. Seemingly obscure restrictions and syncretisms are taken quite seriously and play important roles in his analyses. He has a strong commitment to the existence of a universal set of principles, so that evidence from any language can have implications for any other; in most of his articles he employs evidence from some Romance language to support a proposal based mainly on a Germanic one, or vice-versa. The acuity with which he does this reveals a deep understanding of the fundamental structure of Romance and Germanic languages, and that is always at the forefront of Tarald's work, though he often summons evidence from other languages, and has lately delved deep into the Bantu languages. He often introduces dialectal data to probe the nature of variation. Systematic correlations of surface patterns are vital, and his analyses weave these together in intricate ways. He has a scientist's instinct for the beauty of elegant explanations of complex natural phenomena, and at the same time he easily handles the complex and sometimes arcane mechanisms of current formal theory. He is an early adaptor, drawing freely on proposals in the current literature for descriptive mechanisms and explanatory principles and borrows them without dogmatic allegiance to one framework or another.

Following in the footsteps of Ragnar the viking eleven hundred years earlier, Tarald travelled to Paris, taking up the study of syntax with Richie Kayne. Then, like Leif Eiríksson in the tenth century, Tarald discovered North America, 
studying with Noam Chomsky at MIT in the late seventies and early eighties, establishing himself as a presence in the US theater of Generative Linguistics.

Three of Tarald's early papers, in particular, were highly influential in the development of Principles and Parameters theory (Taraldsen 1978, 1980, 1981b), as can be seen by the citations in Chomsky's classic (1981) Lectures on Government and Binding and other works from that era.

His 'Scope of wh movement' paper (published in Linguistic Inquiry in 1978) supported an expanded role for a unified theory of movement, and a commensurately restricted role for competing deletion rules. In that paper, he argued that Norwegian relative clauses with som involved wh-movement of an unpronounced operator, making their structure more clearly parallel to that of the embedded question in (1) (from Taraldsen 1978, 633).

(1) Jeg lurer på hvem som ser mest svensk ut.

I wonder on who as sees most Swedish out

'I wonder who looks the most Swedish'

He connected the distribution of som in cases like (1) with the French que/qui alternation, where qui appears when a subject is extracted, a topic to which he was to return on numerous occasions in subsequent years, and which is addressed in some of the chapters in this book.

In that paper he also noted in passing that extraction from relative clauses is possible in Norwegian, under certain circumstances, as in (2) (from Taraldsen 1978, 627, n. 6).

(2) noe underlig krydder som jeg vet om en butikk som selger billig some strange spices as I know about a store as sells cheap (*'some strange spices that I know of a store that sells cheaply')

This observation grew into a major topic of investigation in subsequent papers, as noted below.

Tarald's linking of pro-drop to featural properties of inflection and in particular agreement (in 'On the Nominative Island Condition, vacuous application and the that-trace filter,' Taraldsen 1980, first circulated in 1978) has had enormous influence, and is still known as 'Taraldsen's Generalization.' In that paper, he suggested that Italian-style pro-drop was not simply due to a surface rule of pronoun deletion, but involved a null category formally licensed by coindexation with the agreeing inflected verb; as he observed, this was a formalization of a traditional intuition that the rich agreement of languages like Italian obviates the need for an overt subject, and showed how the formal licensing analysis captured correlated properties such as absence of that-trace effects in the Italian-like languages.

The understanding of the that-trace effect in terms of a more general condition on subject licensing (specifically the nominative island constraint), rather than as parochial surface filter, was an example of how to expand locality theory to account for phenomena, rather than listing individual ad hoc surface observations as rules, and hence was part of a much larger shift away from 
language-specific rules and filters toward a more explanatory system.

His discovery of parasitic gaps and their properties, presented at the Pisa GLOW conference in 1979 ('The theoretical interpretation of a class of "marked" extractions,' Taraldsen 1981b) was also immensely important. There, he showed that a peculiar class of of gaps not derived by the regular movement of overt A-bar operators (illustrated in (3), from Taraldsen 1981b, 491) were subject to the same kinds of locality conditions, substantially improving our understanding of the nature of those constraints.

(3) Han er en mann som alle som kjenner, beundrer.

he is a man who all as know admire

'He is a man who everybody who knows admires'

For example, he pointed out that the 'parasitic' gap in the relative clause here must be in the object position, not the subject position, as witnessed by the fact that the sentence cannot mean the same as 'He is a man who everybody who he knows admires.'

In that same paper, he expanded substantially on the status of extraction from relative clauses in Norwegian, as illustrated in (4) (from Taraldsen 1981b, 487).

(4) Julenissen bor det mange barn som kjenner i dette strøket. Santa.Claus live it many children who know in this neighborhood 'There are many children who know Santa Claus living in this neighborhood'

For several years the significance of this kind of data for parametric theory was the subject of a heady debate (and the debate continues; see Cinque 2010).

In many cases he revisits old assumptions and revises or updates them, but never to toot his own horn. In fact, he cites himself remarkably sparingly. He has returned many times to the topics of extraction from relative clauses (Taraldsen 1982) and subject extraction, including the that-trace phenomenon and the distribution of elements like Norwegian som (see especially 'Som and the binding theory,' Taraldsen 1986a), Danish der (especially Taraldsen 1992), French qui (especially Taraldsen 2001), and related elements in dialectal varieties (for Vallader, see for example Taraldsen 2002). In Taraldsen (1981a), he observed the existence of dialects of Norwegian without a that-trace effect, and provided an analysis relating this to other properties of the dialect.

In 1981 Tarald took up a position at the University of Troms $\varnothing$, and Troms $\varnothing$ has been his base of operations ever since. Starting with Taraldsen (1981c), he produced a series of articles examining more general conditions on the licensing of arguments and empty categories, in particular dealing with Norwegian lacausatives (Taraldsen 1983b, 1991a) and complex passives (Taraldsen 1984). These topics are woven together into a coherent narrative with his earlier stories about subject extraction and agreement in the thesis he submitted to University of Troms $\emptyset$ for his doctoral degree, Parametric Variation in Phrase Structure: A Case Study (Taraldsen 1983a). 
Tarald wrote one particularly influential paper together with Kirsti Koch Christensen (Christensen and Taraldsen 1989), showing how structure-dependent agreement on participles in various dialects of Norwegian sheds light on the nature of feature-passing in expletive chains; for instance, they observed the correlation exhibited in (5), where dialects which use 'there' as an expletive normally have agreement on the participle with a lower associate, as in (5-a), while dialects which use 'it' as an expletive require overt movement in order for agreement to appear.

$$
\begin{aligned}
& \text { a. Der er nett komne nokre gjester. } \\
& \text { there is just arrived.PL some guests } \\
& \text { 'There have just arrived some guests' } \\
& \text { b. Det er nett kome nokre gjester. } \\
& \text { it is just arrived some guests } \\
& \text { 'There have just arrived some guests' }
\end{aligned}
$$

He has followed up with further explorations of the nature of expletive chains (Taraldsen 1991b) and of participial small clauses with the verb $f a{ }^{\circ}$ 'get' (Taraldsen 1995b, 2010c). For example, he analyzed the structures represented in (6), where the first is ambiguous between a subject control reading and reading where someone other than the subject did the fixing, while the second only has the second reading.

$$
\begin{aligned}
& \text { a. Jens fikk reparert bilen. } \\
& \text { Jens got repaired the.car } \\
& \text { 'Jens got his car fixed' } \\
& \text { b. Jens fikk bilen reparert. } \\
& \text { Jens got the.car repaired } \\
& \text { 'Jens had his car fixed' }
\end{aligned}
$$

Another major contribution has been to the understanding of verb-second (V2), a topic he explored in 1980 (published as Taraldsen 1989) and developed further in Taraldsen (1985). This investigation culminated in the highly influential 'On verb second and the functional content of syntactic categories' (Taraldsen 1986c), where he argued (following a suggestion by Kayne) that the movement of the verb to $\mathrm{C}$ in $\mathrm{V} 2$ languages is driven by a basic difference between arguments, which are nominal, and predicates, which are verbal. Roughly speaking, a complementizer in $\mathrm{C}$ makes a clause nominal, hence argumental, while a verb in $\mathrm{C}$ makes a clause verbal, hence predicative. More specifically, Tarald suggested that movement of $\mathrm{V}$ to $\mathrm{C}$ made the specifier of $\mathrm{C}$ an $\mathrm{A}$-position, and unified Norwegian topicalization constructions with Italian clitic left-dislocation constructions as analyzed by Cinque (1986).

$$
\begin{aligned}
& \text { Questi libri, Gianni li ha letto. } \\
& \text { these books, Gianni them has read } \\
& \text { 'These books, Gianni has read' }
\end{aligned}
$$

Tarald has also made significant contributions to the discussion of DP structure 
(Taraldsen 1990, 1991c), showing how Norwegian possessor constructions and definite affixes motivate a particular structure of the DP, and relating this to the structure of the clause and the licensing of subjects. The 1990 article, 'Dprojections and N-projections in Norwegian,' is a key reference for the widely adopted DP hypothesis. His Taraldsen (2012) injects a new and radical perspective on DP structure, suggesting that all noun phrases underlyingly involve relative clause structures.

Another cluster of Tarald's papers examines issues concerning reflexive, pronouns, and agreement (Taraldsen 1994, 1996b) and related issues, including the licensing of arguments and the role that case assignment plays there; some examples are Taraldsen $(1986 \mathrm{~b}, 1995 \mathrm{a})$. The latter article in particular ('On agreement and nominative objects in Icelandic') is widely cited and the proposal there to split Agr into person and number heads has had great impact.

I characterized Tarald's approach above as epitomizing the 'Principles and Parameters' perspective, but as the field has grown more 'Minimalist,' so has Tarald's outlook (see his 1996a review of Chomsky's 1995 Minimalist Program, entitled 'How to keep linguists happy'). The Minimalist movement has invited a wholesale rethinking of seemingly established principles, something which Tarald is unquestionably good at. Minimalist work, to an even greater extent than classic Principles and Parameters work, attempts to get a minimal number of mechanisms to carry a maximal empirical load. This is evident in many of his recent papers in which he examines issues of word order and the organization of the morphological spell-out of syntactic structures, including Taraldsen (2000, 2005, 2009, 2010a,b), and Taraldsen and Medová (2007).

\section{Overview of the chapters}

The chapters in this volume show a range of styles, reflecting the diverse personalities of their authors, but all exhibit many of the same virtues as Tarald's papers. The authors each have their distinctive preoccupations, but all are similarly committed to a broadly Minimalist system of universal Principles (of linearization, of locality, of category) and variable Parameters (which might well be located in the featural makeup of functional heads and lexical items, as in Borer's 1984 conjecture). The chapters have differing relations to the Cartography enterprise launched by Rizzi and Cinque; some chapters are clearly cartographic, some are anti-cartographic, and some pursue concerns which run orthogonally to the concerns of Cartography.

Here I briefly describe all nine papers to show how they are connected, then I proceed to give a slightly more detailed characterization of each paper in turn.

The first three papers treat topics which have been central to Tarald's research from the start, including subject extraction and the que/qui alternation.

Rizzi reviews evidence for Criterial Freezing, and argues that straightforward subject extraction is never possible. Rizzi shows some ways in which the effects of subject extraction can be achieved, including a kind of CP-recursion, in the case of fronted adverbials, and subextraction (stranding a phonologically empty 
shell), for the case of clefts.

Koopman \& Sportiche present a radical new analysis of qui in French. In their analysis, French does not allow subject extraction at all, using a special strategy involving a kind of relativized small clause to give the illusion of subject extraction.

Belletti reviews experimental evidence for the preference of subject relatives over object relatives, arguing that the preference is due to the non-local relation which comes about in object relatives, where the object has to cross the subject. She suggests that a smuggling analysis of passives explains why passives are employed in a preferred strategy for expressing the content of object relatives.

The paper by Roberts discusses Taraldsen's Generalization in the light of the development of pro-drop in various Romance languages, including its loss in some cases, mainly French and Brazilian Portuguese. He argues that the specifics of pro-drop in a given language come from an interplay of the featurechecking environment of the clausal architecture and the availability of different classes of pronouns in the language.

The Roberts paper thus deals as much with properties of subjects as with pronouns. This links it thematically to the first trio of papers. At the same time, it is connected to the following two papers, which promote pronominal analyses of complementizers.

Both of those papers, by Manzini and by Kayne, challenge received wisdom concerning the category of complementizer. Manzini's contribution argues that what are commonly analyzed as complementizers in Romance are not part of the clausal structure at all, but are fundamentally nominal. She shows how existing and non-existing syncretism patterns in different Italian dialects reveal that function words like (Standard Italian) che are nominal even when used to introduce finite clauses, and proposes that 'complementizer' che takes the embedded sentence as its complement.

Similarly, Kayne argues that the English complementizer that is a pronoun, not the highest inflectional head in the extended projection of the verb. Thus both Kayne and Manzini pursue analyses that run counter to the usual cartographic line of approach, since cartography tends to focus on the intrinsic hierarchy within a single extended projection, while these papers suggest that identifying the extended projection itself is more complex than usually assumed. More specifically, Kayne argues that that is a relative pronoun, and he argues furthermore that what appear to be complement clauses actually involve relative clause structures.

A final trio of papers in the volume directly addresses the relationship of morphemes and syntactic structure, a topic which has been important to some of Tarald's most recent work.

One paper, Cinque's, develops a theory to derive the crosslinguistic ordering possibilities for morphemes expressing tense, mood and aspect (TMA). The assumption is that each such morpheme directly represents a functional head, organized in a universal hierarchy; the mechanisms governing the structure of words are exactly those governing the structure of phrases.

Another paper, that of Holmberg, examines some morphemes in Finnish 
which, he argues, work differently from the TMA ones discussed by Cinque. Holmberg shows how enclitics indicating interrogative force and focus structures are better analyzed as attaching to the target of attraction, than as representing the head providing the landing site.

A third paper, that of Williams, argues furthermore that the properties of a prefix like re-cannot be derived by simply locating it in an extended functional sequence which includes TMA functors. Instead, Williams argues, a notion of word is necessary, with its own internal structure, suggesting a limit on the cartographic enterprise as commonly practiced.

\section{Rizzi: Some consequences of Criterial Freez- ing}

Rizzi revisits subject extraction from the perspective of Criterial Freezing. Criterial Freezing is a phenomenon whereby a phrase attracted to a position associated with scopal or discourse-informational effects is frozen in place (Rizzi and Shlonsky 2007). He argues that the canonical subject position is Criterial, which means that subjects can never be extracted directly from that position (the specifier of a clausal head $\mathrm{D}_{\mathrm{Subj}}$, in his analysis).

He suggests that there are two broad strategies for effecting subject extraction. One, he calls the 'Fixed' strategy, where a subject enters an A'-dependency without movement, through the use of a resumptive element. The other, he calls the 'Skipping' strategy, where an expletive occupies the specifier of $\mathrm{D}_{\mathrm{Subj}}$, allowing the thematic subject to be extracted from a lower position, skipping the canonical subject position. As Rizzi notes, this is the strategy that Tarald argued for Norwegian and Danish in his 1986a and 2001 papers. In those papers, Tarald had to afford the Danish expletive der and the Norwegian som, in cases of subject extraction, a special status straddling the C-system and the I-system. As Rizzi observes, this situation is natural in the current light of a finely decomposed C-structure and a finely decomposed I-structure.

He extends a version of Tarald's solution to the English that-trace phenomenon, suggesting that English has a null counterpart to Norwegian som to license subject 'skipping' (i.e. a null Fin element which is adjacent to, and the checks the Criterial feature of, $\left.\mathrm{D}_{\text {Subj }}\right)$; overt that can also move to Force, but the null complementizer cannot, which is why overt that is required in extraposed clauses, clauses used as subjects, and so on.

Rizzi goes on to treat two phenomena which are important to the understanding of Criterial Freezing as it applies to subjects. The first is the adjacency effect, whereby a left-peripheral clausal adverbial ameliorates the that-trace effect. This he analyzes in terms of a kind of CP-recursion. The second is the apparent possibility of $w$ h-extracting the focus of a cleft, which must be a Criterial position given its more general characteristics. This he analyzes in terms of 'subextraction' (extraction of a subpart of the focus, leaving a possibly empty shell behind) or of 'superextraction' (extraction of a larger constituent contain- 
ing the focus). In both cases, strict locality effects are expected, and Rizzi demonstrates that they are present.

\section{Koopman and Sportiche: The que/qui alter- nation: New analytic directions}

Koopman \& Sportiche present a novel analysis of the que/qui alternation in long subject extraction in French. They suggest that contrary to appearances, there is no long subject extraction in French.

This analysis challenges previous proposals concerning the distribution of subject gaps, including Tarald's and Rizzi's. Koopman \& Sportiche point out that on those proposals, special complementizers or expletives eliminate the need for a trace in the subject position, allowing 'Skipping' in Rizzi's terms, whereby the thematic subject moves from a lower, nonsubject position.

Instead, the French strategy for expressing what would be expressed by long subject extraction involves what is known as a Pseudo-Relative Small Clause (PRSC). The PRSC consists of a small clause subject plus a predicate which is formed from a relative clause. The subject of the relative clause does not leave the relative clause itself; in this sense this is an example of what Rizzi calls a 'Fixed' strategy, where the finite clause subject enters into a chain relationship without moving. But since what is actually extracted is a small clause subject, this is also an example of what Rizzi calls 'truncation': subjects of clauses which are smaller than a full finite clause are not Criterial, in his terms, and hence are not frozen in place.

Koopman \& Sportiche demonstrate at length that the contexts in which apparent subject extraction is allowed are more restrictive than ordinary bridge contexts. First, the class of predicates allowing embedded subject extraction is highly similar to the class which allows EECM (Exceptional ECM, whereby an ECM subject is allowed only in case it is $\mathrm{A}^{\prime}$-moved). Second, subject extraction shows a sensitivity to interveners (negation and quantifiers) which is shared by EECM constructions and not by extraction of nonsubjects from embedded finite clauses. They show that Dutch and West Flemish manifest parallel patterns.

\section{Belletti: Notes on passive object relatives}

Belletti addresses the well-established asymmetry between subject relatives and object relatives. Cross-linguistically, object relatives are more restricted than subject relatives in various ways, for example many languages allow subject relatives but not object relatives (Keenan and Comrie 1977), and even in languages which allow object relatives, they can be shown to be more difficult to process and to produce.

Belletti reports on the results of an experiment in which children were induced to produce sentences containing relative clauses. Under various conditions, they avoided the production of object relatives, and frequently settled on 
a passive strategy: by passivizing a clause, speakers can produce a subject relative with the same basic content as a corresponding active voice object relative.

Belletti argues that the problem with object relatives is essentially one of locality, as it requires an object to be extracted across a subject. She suggests that a smuggling analysis of passive (Collins 2005) explains how the locality problem is overcome in a passive object relative: The object is moved across the ( $v$ P-internal) subject inside a VP, avoiding a Relativized Minimality violation. The object then escapes the VP to occupy the subject position without crossing any argument (this recalls Tarald's 2010a use of smuggling in his analysis of case-licensing of the object above the base position of the subject).

Interestingly, Belletti's analysis suggests that a canonical subject (usually taken to be an A-position) creates a Minimality problem for the formation of an object relative (usually taken to be an $\mathrm{A}^{\prime}$-movement). This might strengthen the case for the subject position being a criterial position in Rizzi's sense, since other criterial positions typically exhibit $\mathrm{A}^{\prime}$ properties.

\section{Roberts: Taraldsen's Generalisation and lan- guage change: Two ways to lose null subjects}

Roberts discusses Taraldsen's Generalisation, an early observation about the relation between rich agreement and pro-drop. He takes up two case studies, those of French and Brazilian Portuguese, showing that they followed very different routes from their Latin origins, leading to the current state of affairs in which French is a non-null-subject language, like English, while Brazilian Portuguese is a partial null-subject language, like Finnish and Hebrew.

Roberts argues that the loss of null subjects in French is not directly related to the weakening of the agreement system. Instead, it is more directly related to the period in the history of French where null subjects were licensed in a V2 configuration; the morphologically inflected finite verb had to occupy the $\mathrm{C}$ position in order to license a null subject in the lower canonical subject position (whether this kind of licensing under V2 is somehow related to the weakening of the agreement system remains to be seen).

As French lost its V2 properties, the conditioning environment for null subjects was lost, and a series of weak pronouns were recruited and adapted to fill the functions previously served by pro, leading to the system of Standard French today. Thus it can be said that French lost the formal licensing condition for pro, in the terms of Rizzi (1986).

Brazilian Portuguese, on the other hand, followed a very different route. Roberts shows that the pronominal system was restructured, and he argues that this led to a kind of Impoverishment rule, in the sense of Distributed Morphology: learners analyzed the defective pronominal system in terms of a syncretism-flattening rule of $\phi$-feature deletion. Roberts argues that referential D-features require a full complement of $\phi$-features, so that the Impoverishment rule effectively ruled out the possibility for referential pro; a loss of formal 
identification, in Rizzi's 1986 terms. Pro continued to be formally licensed, and so continued to be used in cases where it was independently identified (as in first and second person singular) or did not need identification (as in expletive and impersonal contexts), leading to the current partial pro-drop system of Brazilian Portuguese.

Roberts concludes that Taraldsen's Generalization is correct in its essentials, but that it plays a lesser role than usually assumed in cases like the French one.

\section{Manzini: The Romance $k$ - complementizers}

Manzini argues that the complementizers in Romance and Germanic languages are not functional categories high in the embedded clause, but nominal projections which satisfy the argument structural requirements of the selecting verb. She supports this analysis with a wealth of microcomparative data showing that the patterns of distribution of different complementizer types are quite systematic.

Focusing on Italian che and related forms in Italian dialects (often pronounced $/ \mathrm{ka} /, / \mathrm{kə} /, / \mathrm{ki} /$, or variants beginning with $/ \mathrm{t} / /$; collectively the $k$ complementizers), Manzini suggests that in their guises as nominal elements (e.g. meaning 'what' or 'which') they quite generally serve as operators binding different kinds of argumental variables, and that this analysis can be straightforwardly extended to their use as complementizers, allowing a unified treatment of what are normally taken to be quite distinct uses.

She shows how extensive microcomparative data backs this up; many dialects show an opposition between two or more forms, for example $k a$ and $k i$, and the distribution of labor between the forms is far from arbitrary. Furthermore, it is not what would be expected if the clause-introducing function were systematically distinct from the $w h$-uses. Instead, the $w h$-uses typically either syncretize with the complementizer used in irrealis-type modal contexts, or with temporal adverbial clause introducers. Manzini argues that the observed patterns of syncretism can only be explained on a nominal analysis of these elements.

Even where modality is implicated, the distribution of the multiple forms of $k$-complementizers fails to line up neatly with verbal inflectional features like indicative and subjunctive mood; the relationship is more intricate. Here she touches on the interaction with complementizer drop and its relation to $\mathrm{V}$ to $\mathrm{C}$ movement. Manzini also discusses interrogative complementizers corresponding to 'if' and 'whether' and shows that they can be analyzed in this system in terms of polarity sensitivity.

Manzini also addresses the apparent connection between complementizers and finiteness, a fact which on the face of it would seem to support the analysis of complementizers as part of the verbal system. She points out that the purported finite complementizer can be used with inflected infinitives, when those are found, suggesting that the connection to finiteness is indirect at best. Instead, the $k$-type complementizers are sensitive to the way the subject position is filled, because they are sensitive to the propositional completeness of their sentential 
complement.

This latter discussion touches on the analysis of the that-trace effect, bringing it further into contact with Tarald's earlier work.

\section{Kayne: Why isn't this a complementizer?}

In this rich and dense paper, Kayne lays out an argument that the that which introduces relative clauses is not a complementizer (an assumption widely held since Klima 1965), but is in fact a relative pronoun. He takes up Klima's arguments against this position, and systematically shows one by one that they are not conclusive.

For example, relative pronouns in other languages show agreement with the head noun, as Kayne illustrates with Dutch, where dat alternates with die:
a. het boek dat ik nu lees the book that I now read 'the book that I am reading now'
b. de boeken die ik nu lees the.PL books those I now read 'the books that I am reading now'

In contrast, English has the books \{that/*those\} I am reading, despite having a plural those in other contexts. Kayne argues that adnominal agreement in English is contingent on reaching a certain structural position in the DP, which is unavailable in relative clause structures due to movement of the head noun. He shows that this extends to certain cases of French $c e$. Kayne also shows that there are additional sources of nonagreement, for example, allowing the French que and the Italian che to be analyzed as relative pronouns as well.

Showing that this is marked compared with that, necessarily containing a person feature, Kayne suggests that it, like those, must raise to a high structural position, the same one which is unavailable in relative clauses. This answers the question posed in the title of the chapter, why isn't this a complementizer?

The chapter goes on to suggest (drawing on earlier work such as that of Kiparsky \& Kiparsky and of Rosenbaum) that the that which introduces subordinate clauses in argument positions is also a relative pronoun, in other words subordinate clauses quite generally are covertly relative clause structures.

The chapter provides a terrific companion to Manzini's, with many harmonious points but also several points of contrast. It also draws an interesting counterpoint to Taraldsen's (2012) suggestion that all noun phrases are covertly relative clauses. It raises many interesting and unresolved questions, for example why it is that complement clauses are often permeable for movement, while relative clauses are typically islands (except under certain conditions, as discussed in Taraldsen 1980, 1981b, 1982, cf. (4) above). 


\section{Cinque: Again on Tense, Aspect, Mood mor- pheme order and the "Mirror Principle"}

In this paper, Cinque revisits the order of verbal inflectional morphemes which he examined in Cinque (1999), in the light of the theory of morpheme order developed in Cinque (2005). In the first paper, the usual order of any pairing of [speech act $]$ mood, ${ }^{1}$ tense, and aspect morphemes on the same side of a verb stem was shown to reflect a hierarchy Mood $>$ Tense $>$ Aspect. In the latter paper, Cinque observes that although a hierarchy in the noun phrase of Demonstrative $>$ Numeral $>$ Adjective $>$ Noun is well-supported, it is not always the case that the higher categories are further from the lexical head (the noun, in that case) than the lower categories are. In Cinque (2005), a theory is developed to account for all and only the orders attested in the noun phrase, and in this paper the same theory is shown to account for all and only the attested orders of Mood, Tense, and Aspect morphemes. The theory assumes a rigid Antisymmetry and a system of movement constrained by certain assumptions about what feature can be attracted and what can be pied-piped.

Specifically, the lexical core of the clause (VP) can move to various heights in the extended projection (a slight difference between the current chapter and the 2005 analysis is that here, the lexical core moves as a phrase, much as in Tarald's 2000 analysis of V-raising as VP movement), and at each step it can pied-pipe or not. Pied-piping is the carrying along of superordinate material, and can be either of two varieties, depending on whether the attracted element is in a complement position compared to the superordinate material ("picture of who" pied-piping) or the attracted element is in a specifier position ("whose picture" pied-piping).

Cinque shows that an investigation of hundreds of unrelated languages reveals orders compatible with the above assumptions, deriving exactly the thirteen patterns predicted to exist, out of 24 logically possible orders for the four elements. He identifies a few apparent counterexamples, and shows that generally, when those cases are examined more closely, there is independent evidence for focus-based movement of an inflectional element to the left of superordinately higher functional heads, a movement independently known to exist.

\section{Holmberg: On the Syntax of the Finnish Question Particle}

Holmberg discusses a class of second-position clitics in Finnish, mainly having to do with focus and question formation. The standard analysis of the question marker - $k o$ is that it is the overt spelling out of $\mathrm{C}$, accompanied by the attraction of a targetted element to SpecCP. However, Holmberg argues, the standard

\footnotetext{
${ }^{1}$ By this term Cinque refers to morphemes which class a clause as interrogative, declarative, imperative, etc.
} 
analysis does not account for the detailed distribution of $-k o$, nor for the possible readings which arise concerning the scope of focus.

To solve the problem, he takes a closer look at some subtle differences between the focus clitic -kin and the question marker -ko. Like -ko, -kin can be broadly described as following a focused constituent, but unlike - ko, - kin does not involve movement to the left periphery of the clause (hence no secondposition effect). Holmberg shows how -kin can be analyzed as merging in a position c-commanding a constituent with a Focus feature.

Comparing - $k o$ and -kin more closely, it emerges that -ko, unlike -kin, must be immediately preceded by a constituent. Holmberg argues that this shows that the placement of $-k o$ involves movement in a way that is not motivated in cases with -kin. That is, -kin merges into a position which locally c-commands Focus, while - $k o$ merges in a $\mathrm{D}$ position and attracts a constituent which contains Focus to its specifier. This analysis is combined with the independent movement of the constituent containing - $k o$ to the left periphery, accounting for the Finnish data patterns observed in an elegant fashion.

\section{Williams: Derivational prefixes are projec- tive, not realizational}

Williams, in his contribution to this volume, investigates the properties of the English prefix re-, and compares it to a similar prefix in Greek (and more briefly to counterparts in German and Warlpiri).

The prefix re-introduces a presupposition that something has happened before. Williams argues that the presupposition is determined by the lexical content of the verbal word to which the prefix attaches, rather than by a finegrained functional structure of the type that is central to work in Cartography.

For example, He repainted a house white presupposes that a house is being affected for at least the second time, but the house in question need not have been white before; so the secondary predicate white is outside the presupposition. However, in He rewhitened a house, the result is part of the verbal word, and the property it describes (whiteness) is included in the presupposition of re-.

Williams argues that these facts cannot be adequately captured in an approach in which re- is simply located at a particular height in a functional sequence of heads which are realized various as prefixes, suffixes, or independent words. In fact, the scope of re- is not determined by the functional structure at all. Instead, Williams argues, the word must be recognized as the domain in which re- is interpreted, and a system or module of word-formation must be recognized which feeds into syntax (Williams calls this system Derivational Morphology, contrasting it with Distributed Morphology, and appropriating the abbreviation "DM"). He suggests that this motivates a fresh look at the status of the contrast between derivation and inflection, which has been rejected by researchers working in a variety of frameworks. 
Williams' argument sets a limit on the decompose-and-project enterprise which has characterized much work in Cartography. If his account is correct, it suggests that there are complex words whose internal structures do not directly interact with syntax, which has very serious implications for much current work in syntax.

\section{Conclusion}

The chapters in this volume are of the highest quality, and reflect both the breadth and the depth of Tarald's contributions to the field. As is often the case in any science, the results of the individual studies are not necessarily compatible with each other, but introduce many tensions and even outright contradictions. This is naturally true of their relationship to Tarald's work as well. The questions that are raised are as much of the long-term legacy of the work as its results.

\section{References}

Chomsky, Noam. 1981. Lectures on Government and Binding. Foris, Dordrecht.

Chomsky, Noam. 1995. The Minimalist Program. MIT Press, Cambridge, Ma.

Christensen, Kirsti Koch and Knut Tarald Taraldsen. 1989. Expletive chain formation and past participle agreement in Scandinavian dialects. In Dialect Variation and the Theory of Grammar, edited by Paola Benincà, pp. 53-83. Foris, Dordrecht.

Cinque, Guglielmo. 1986. Bare quantifiers, quantified NPs and the notion of operator at S-structure. Rivista di grammatica generativa 11: 9-10.

Cinque, Guglielmo. 1999. Adverbs and Functional Heads: A Cross-Linguistic Perspective. Oxford University Press, New York.

Cinque, Guglielmo. 2005. Deriving Greenberg's Universal 20 and its exceptions. Linguistic Inquiry 36 3: 315-332.

Cinque, Guglielmo. 2010. On a selective "violation" of the Complex NP Constraint. In Structure Preserved: Studies in Syntax for Jan Koster, edited by Jan-Wouter Zwart and Mark de Vries, pp. 81-89. John Benjamins, Amsterdam.

Collins, Chris. 2005. A smuggling approach to the passive in English. Syntax 8 2: $81-120$.

Keenan, Edward L. and Bernard Comrie. 1977. Noun phrase accessibility and Universal Grammar. Linguistic Inquiry 8 1: 63-99.

Klima, Edward S. 1965. Studies in Diachronic Syntax. Ph.D. thesis, Harvard. 
Rizzi, Luigi. 1986. Null objects in Italian and the theory of pro. Linguistic Inquiry 17 3: 501-557.

Rizzi, Luigi and Ur Shlonsky. 2007. Approaching UG from below. In Interfaces + Recursion = Language? Chomsky's Minimalism and the View from SyntaxSemantics, edited by Uli Sauerland and Hans-Martin Gärtner, pp. 115-160. Mouton de Gruyter, Berlin.

Taraldsen, Knut Tarald. 1978. The scope of Wh movement in Norwegian. Linguistic Inquiry pp. 623-640.

Taraldsen, Knut Tarald. 1980. On the Nominative Island Condition, vacuous application and the that-trace filter. IU Linguistics Club. Indiana University Linguistics Club, Bloomington.

Taraldsen, Knut Tarald. 1981a. Case conflict in Norwegian topicalization. In Proceedings of the 11th Annual Meeting of NELS, edited by Victoria Burke and James Pustejovsky, pp. 377-398. UMass, Amherst, Ma.

Taraldsen, Knut Tarald. 1981b. On the theoretical interpretation of a class of marked extractions. In Theory of Markedness in Generative Grammar: Proceedings of the 1979 GLOW Conference, edited by Adriana Belletti, Luciana Brandi, and Luigi Rizzi, pp. 475-516. Scuola Normale Superiore di Pisa, Pisa.

Taraldsen, Knut Tarald. 1981c. Remarks on government, thematic structure, and the distribution of empty categories. In Levels of Syntactic Representation, edited by Robert May and Jan Koster, pp. 253-291. Foris, Dordrecht.

Taraldsen, Knut Tarald. 1982. Extraction from relative clauses in Norwegian. In Readings on Unbounded Dependencies in Scandinavian Languages, edited by Elisabet Engdahl and Eva Ejerhed, pp. 205-222. Almqvist \& Wiksell, Stockholm.

Taraldsen, Knut Tarald. 1983a. Parametric Variation in Phrase Stucture: A Case Study. Ph.D. thesis, University of Troms $\varnothing$.

Taraldsen, Knut Tarald. 1983b. Some phrase structure dependent differences between Swedish and Norwegian. Working Papers in Scandinavian Syntax 9: $1-45$.

Taraldsen, Knut Tarald. 1984. Remarks on complex passives. In Riepmočála: Essays in Honour of Knut Bergsland, edited by Bernt Brendemoen, Even Hovdhaugen, and Ole Henrik Magga, pp. 153-164. Novus, Oslo.

Taraldsen, Knut Tarald. 1985. Ka du trur? In Heidersskrift til Kåre Elstad, edited by Tove Bull and Anton Fjeldstad, pp. 37-47. Institutt for språk og litteratur Universitetet i Troms $\varnothing$, Troms $\varnothing$.

Taraldsen, Knut Tarald. 1986a. Som and the Binding Theory. In Topics in Scandinavian Syntax, edited by Lars Hellan and Kirsti Koch Christensen, pp. 149-184. Reidel, Dordrecht. 
Taraldsen, Knut Tarald. 1986b. On the distribution of nominative objects in Finnish. In Features and Projections, edited by Pieter Muysken and Henk van Riemsdijk, pp. 139-161. Foris, Dordrecht.

Taraldsen, Knut Tarald. 1986c. On verb second and the functional content of syntactic categories. In Verb Second Phenomena in Germanic Languages, edited by Hubert Haider and Martin Prinzhorn, pp. 7-25. Foris, Dordrecht.

Taraldsen, Knut Tarald. 1989. Subject/verb inversion and V-movement. In Syntaks/Syntax, edited by Ernst Håkon Jahr and Ove Lorentz, pp. 274-294. Novus, Oslo. Ms. 1980.

Taraldsen, Knut Tarald. 1990. D-projections and N-projections in Norwegian. In Grammar in Progress, edited by Joan Mascarò and Marina Nespor, pp. 419-432. Foris, Dordrecht.

Taraldsen, Knut Tarald. 1991a. A directionality parameter for subject-object linking. In Principles and Parameters in Comparative Grammar, edited by Robert Freidin, pp. 219-268. MIT Press, Cambridge, Ma.

Taraldsen, Knut Tarald. 1991b. NP-movement and expletive chains. In Representation and Derivation in the Theory of Grammar, edited by Hubert Haider and Klaus Netter, pp. 53-69. Kluwer, Dordrecht.

Taraldsen, Knut Tarald. 1991c. Two arguments for functional heads. Lingua 84 2-3: 85-108.

Taraldsen, Knut Tarald. 1992. Second thoughts on der. In Structure de la Phrase et Théorie du Liage, edited by Hans-Georg Obenauer and Anne Zribi-Hertz, pp. 217-249. Presses Universitaires de Vincennes, Saint-Denis.

Taraldsen, Knut Tarald. 1994. Reflexive clitics in two Rheto-Romance dialects. In Paths towards Universal Grammar: Studies in Honor of Richard S. Kayne, edited by Guglielmo Cinque, Jan Koster, Jean-Yves Pollock, Luigi Rizzi, and Raffaella Zanuttini, pp. 395-415. Georgetown University Press, Washington, DC.

Taraldsen, Knut Tarald. 1995a. On agreement and nominative objects in Icelandic. In Studies in Comparative Germanic Syntax, edited by Hubert Haider, Susan Olsen, and Sten Vikner, pp. 307-327. Kluwer, Dordrecht.

Taraldsen, Knut Tarald. 1995b. Participle-based small clause complements of få 'get' in Norwegian. In Small Clauses, edited by Anna Cardinaletti and Maria Teresa Guasti, pp. 207-32. Academic Press, San Diego.

Taraldsen, Knut Tarald. 1996a. How to keep linguists happy: Review of the minimalist program by Noam Chomsky. GLOT International 2 3: 12-15. 
Taraldsen, Knut Tarald. 1996b. Reflexives, pronouns, and subject/verb agreement in Icelandic and Faroese. In Microparametric Syntax and Dialect Variation, edited by James R. Black and Virginia Motapanyane, pp. 189-211. John Benjamins, Amsterdam.

Taraldsen, Knut Tarald. 2000. V-movement and VP-movement in derivations leading to VO-order. In The Derivation of $V O$ and $O V$, edited by Peter Svenonius, pp. 97-122. John Benjamins, Amsterdam.

Taraldsen, Knut Tarald. 2001. Subject extraction, the distribution of expletives, and stylistic inversion. In Subject Inversion in Romance and the Theory of Universal Grammar, edited by Aafke Hulk and Jean-Yves Pollock, pp. 163182. Oxford University Press, Oxford.

Taraldsen, Knut Tarald. 2002. The que/qui alternation and the distribution of expletives. In Subjects, Expletives, and the EPP, edited by Peter Svenonius, pp. 21-35. Oxford University Press, New York.

Taraldsen, Knut Tarald. 2005. Wanna and the prepositional complementizers of English. In Organizing Grammar: Studies in Honor of Henk van Riemsdijk, edited by Hans Broekhuis, Norbert Corver, Riny Huybregts, Ursula Kleinhenz, and Jan Koster, pp. 625-632. Mouton de Gruyter, Berlin.

Taraldsen, Knut Tarald. 2009. Lexicalizing number and gender in Lunigiana. In Tromsø Working Papers on Language and Linguistics: Nordlyd 36.1, Special issue on Nanosyntax, edited by Peter Svenonius, Gillian Ramchand, Michal Starke, and Knut Tarald Taraldsen, pp. 113-127. University of Troms $\varnothing$, Troms $\varnothing$. Available at http://www.ub.uit.no/baser/nordlyd/.

Taraldsen, Knut Tarald. 2010a. Case-alignment and verb placement. In Structure Preserved: Studies in Syntax for Jan Koster, edited by Jan-Wouter Zwart and Mark de Vries, pp. 341-346. John Benjamins, Amsterdam.

Taraldsen, Knut Tarald. 2010b. The nanosyntax of Nguni noun class prefixes and concords. Lingua 120: 1522-1548.

Taraldsen, Knut Tarald. 2010c. Unintentionally out of control. In Argument Structure and Syntactic Relations, edited by Maia Duguine, Susana Huidobro, and Nerea Madariaga, pp. 283-302. John Benjamins, Amsterdam.

Taraldsen, Knut Tarald. 2012. The structural object position of verbs and nouns. In Functional Heads: The Cartography of Syntactic Structures, Volume 7, edited by Laura Brugé, Anna Cardinaletti, Giuliana Giusti, Nicola Munaro, and Cecilia Poletto, pp. 263-274. Oxford University Press, Oxford.

Taraldsen, Tarald and Lucie Medová. 2007. The Czech locative chameleon. In Tromsø Working Papers on Language and Linguistics: Nordlyd 34.2, Special issue on Space, Motion, and Result, edited by Monika Bašić, Marina Pantcheva, Minjeong Son, and Peter Svenonius, pp. 300-319. University of Troms $\varnothing$, Troms $\varnothing$. Available at http://www.ub.uit.no/baser/nordlyd/. 